\title{
Opportunities for Intervention Strategies for Weight Management: Global Actions on Fluid Intake Patterns
}

\author{
Max Lafontan ${ }^{a} \quad$ Tommy L.S. Visscher $^{b} \quad$ Nathalie Farpour-Lambert ${ }^{c}$ \\ Volkan Yumuk ${ }^{d}$ \\ ${ }^{a}$ Inserm/University Paul Sabatier UMR 1048, Institute of Metabolic and Cardiovascular \\ Diseases, Hôpital Rangueil, Toulouse cedex, France; ${ }^{b}$ Research Centre for the Prevention \\ of Overweight, Windesheim University of Applied Sciences and VU University, Zwolle, \\ the Netherlands; ' ${ }^{C}$ Service of Therapeutic Education for Chronic Diseases, Department \\ of Community Health, Primary Care and Emergency, University Hospital of Geneva and \\ University of Geneva, Geneva, Switzerland; d Division of Endocrinology, Metabolism and \\ Diabetes, Istanbul University Cerrahpasa Medical Faculty, Istanbul, Turkey
}

\section{Key Words}

Hydration · Fluid intake $\cdot$ Overweight $\cdot$ Water $\cdot$ Beverages

\begin{abstract}
Summary: Water is an essential nutrient for all physiological functions and particularly important for thermoregulation. About $60 \%$ of our body weight is made of water. Under standard conditions $\left(18-20^{\circ} \mathrm{C}\right.$ and moderate activity), water balance is regulated within $0.2 \%$ of body weight over a 24 -hour period. Water requirement varies between individuals and according to environmental conditions. Concerning considerations related to obesity, the health impact of fluid intake is commonly overlooked. Fluid intake advices are missing in most of food pyramids offered to the public, and water requirements and hydration challenges remain often neglected. The purpose of this paper is to emphasize and discuss the role of water consumption in the context of other important public health measures for weight management. Attention will be focused on fluid intake patterns and hydration-related questions in the context of global interventions and/or physical activity programs settled in weight management protocols.
\end{abstract}

(c) 2015 S. Karger GmbH, Freiburg

\section{Introduction}

The prevalence of overweight was higher among men in all 36 European countries, and prevalence of obesity was also higher in men in 14 of 36 countries [1]. Until now the geographical zones protected from the epidemics are only located in some desert areas of 
Lafontan et al.: Opportunities for Intervention Strategies for Weight Management: Global Actions on Fluid Intake Patterns

Africa often characterized by food shortage periods and famine. The increased prevalence of overweight and obesity in children and adults has been examined in most EC countries [2-6]. In light of the immigration drive towards EC countries, some national discrepancies must be considered. For example, a declining prevalence of overweight is observed in Dutch girls while in Turkish children living in the Netherlands overweight prevalence and obesity is high and increasing [7].

Questions remain largely open concerning the determinants of the obesity pandemic which cannot have its cause in a shift of a genetic makeup although some epigenetic alterations cannot be excluded [8]. Globalization of westernized behaviors has led to food security and reduction of poverty; however, this is also associated with detrimental effects such as increased consumption of sugar-sweetened beverages (SSBs), increased portion sizes, calorie-dense foods, and low-cost high-energy food of poor nutritional quality. An increased number of meals consumed throughout the day is observed. A recent study has shown that Western-style fast food intake increases the risk of developing cardiometabolic diseases in an Eastern population [9]. Curiously, it was noted that, in contrast to the USA where fast food consumption tends to be higher among people with lower education and poor economic status, consumers in Asian countries were more educated, smoked less, and were more physically active [10]. This is a point which strengthens the association between fast food consumption and cardiometabolic risks, irrespective of other social determinants. Differential trends towards obesity expansion have been reported according to the economic status in a number of countries including such of the EC; high prevalence of obesity is observed in socioeconomically disadvantaged populations [1]. Social inequalities in overweight and obesity have persisted even in EC Nordic countries that are considered to be affluent and reputedly the most egalitarian in the Western world [11]. In addition to the most currently proposed reasons to explain the increased prevalence of obesity (i.e., deleterious food marketing practices leading to purchase of increased portions of energy-dense items and drastic reduction of physical activity), alternative contributors to the obesity epidemic must also be considered as done in two recent reviews $[12,13]$.

An increasing prevalence of cardiovascular risk factors and the metabolic syndrome due to changes in diets and lifestyle is commonly described. Trends and risk factors have been extensively considered and discussed in a number of review articles [14-17]. Some recent reports have claimed that the obesity epidemic seems to have stabilized since the end of the 20 th century $[18,19]$. However, some biases in the data which could explain this trend have recently been proposed and discussed. Focusing on trends in waist circumference rather than BMI leads to a less optimistic conclusion: the public health problem of obesity is still increasing [20]. An alarming upward trend of more severe forms of childhood obesity has been reported in the USA (i.e., from the National Health and Nutrition Examination Survey, 1999 to 2012) [21]. Problems in population sampling and the low participation rate in surveys may mask the evolution of obesity over time. Response rates in health surveys are strongly influenced by degree of fatness, intelligence, educational level, social class, age, and proximity of residence [22]. Additionally, appropriate epidemiological data are not available everywhere.

Once obesity is present, treatment becomes increasingly complex due to biological, physiological, behavioral, and cultural determinants that become entrenched in the long term. Despite some progress in obesity management, there has been a progressive rise in its prevalence that has spread to developing countries. Once an individual becomes obese, it is difficult to lose weight and maintain a lowered body weight. Limiting weight gain in the long term by early nutritional and behavioral interventions will reduce the prevalence of obesity among children and adolescents. Preventing and tackling obesity requires coordinated efforts of the health care systems, but efforts will be rather limited if industry and governments are not fully involved. The World Health Organization (WHO Regional Office for Europe), European parliamentarians 
Lafontan et al.: Opportunities for Intervention Strategies for Weight Management:

Global Actions on Fluid Intake Patterns

as well as reports from national agencies in the UK and some other EC countries have concluded that advertising and promotional marketing of foods and beverages have a sufficient negative effect on children's diets to justify action [23]. Population-wide interventions are necessary to promote positive behavioral changes. Moreover, since in utero impacts are probable, it is necessary to implement follow-up of pregnant females and initiate early surveys in childhood obesity to obtain comparable data and to establish feasible intervention strategies.

The purpose of this paper is to present and discuss the role of water consumption in the context of other important public health measures for weight management. Attention will be focused on fluid intake patterns and hydration-related questions in the context of global interventions and/or physical activity programs settled in weight management protocols. Diet-related questions will not be considered in the present review.

\section{Global Strategies: Lifestyle Counseling to Motivate Behavioral Changes}

Large-scale motivation-based intervention programs aimed at modifying lifestyle through behavioral changes have shown some beneficial effects on prevention of overweight and type 2 diabetes. Since adults have higher proportional weight gain than children for the same proportional increase in energy intake, mostly because of a higher fat content of the weight being gained [24], it is important to propose strategies adapted to the age of the target population. Large-scale intervention studies have been implemented in countries such as the USA [25], China [26, 27], Finland [28], and India [29]. Several school-based intervention programs have not shown decreases in the degree of obesity, but rather positive changes in food intake patterns habits in school children in the USA [30,31]. Although effects are rather modest, the global conclusions are encouraging and validate the feasibility and efficacy of such interventions. When the efficacy of an intervention is confirmed, the procedures should be scaled up to the national level and continued on the long term in countries affected by the obesity epidemic. A notable example is the North Karelia Project (launched in 1972) in Finland, which revealed that an integrated community-based intervention on diet and lifestyle can reduce coronary heart disease risk and mortality by $80 \%$ [32]. This ambitious program dramatically modified the social and physical environment of the community after having raised the awareness of the severity of the disease in the population. The essential point of the program was the ability to drive the involvement of the global community to work closely with and maintained adherence to the global project. The partners included health services, schools, supermarkets, food industry, community leaders, local media, and nongovernmental organizations. After successful results during the 5-year intervention, the project was expanded country-wide, and expert guidelines were created [33]. Another example are the studies conducted inside the EPODE (Ensemble, Prévenons l'Obésité Des Enfants) program, a community-based intervention program initiated in France, that has clearly shown that childhood obesity is reduced in towns implicated in the prevention strategies compared with matched control towns. EPODE is now being implemented in more than 293 cities in Europe [34]. This kind of intervention, which requires positive contribution of a large number of partners, must be encouraged. Restriction of unhealthy beverages and food promotion to children requires the voluntary contribution of industry or its control by legislation. Alliances in countries towards such initiatives are essential.

All interventions to favor healthy lifestyles must be designed to influence social, economic, and physical environment. Specific attention must be paid to cultural differences affecting weight loss interventions. Due to immigration, the European population is becoming ethnically diverse. Dietary patterns and weight-related concerns and behaviors differ among adolescents and adults in all ethnic groups. Adapted intervention strategies within targeted 
Lafontan et al.: Opportunities for Intervention Strategies for Weight Management:

Global Actions on Fluid Intake Patterns

populations could be of interest. A recent study revealed that even within a relatively homogenous sociodemographic community (with a high prevalence of adult obesity at $28.7 \%$ ) a range of interventions and messages must be tailored for different population segments that vary in their readiness to change and confidence about tackling obesity [35]. Ethnic differences in weight loss success may also result from a combination of physiological, behavioral, sociocultural, biological, and programmatic factors [36, 37].

\section{Diet Improvements and Physical Activity Are Expected to Have an Impact on Public Health}

Physicians have the responsibility to recognize obesity as a disease and to propose appropriate treatments to their patients. Diet is the leading cause of health loss globally according to the Global Burden of Disease (GBD) 2010 [38]. There is general agreement that messages about food and diet should be supported by national dietary guidelines. Ministers and representatives attending the WHO European Ministerial Conference on Counteracting Obesity (Istanbul, Turkey, November 15-17, 2006) adopted The European Charter on Counteracting Obesity and proposed principles, goals, and framework for action [39]. It was claimed that the obesity epidemic is reversible, and progression toward reversion of the trend, relating to children and adolescents, should be possible by 2020. Among the intervention strategies, improved diet and physical activity are expected to have a significant impact on public health. The changes in Europe achieved since 2006 are rather disappointing. In front of the numerous putative contributors to the obesity epidemic, some factors probably remain neglected [13].

The balance between the responsibilities of individuals, health advocates, governments and society must be clarified. It seems essential to improve mobilization of partners and operational synergies across the different sectors. Professional networks and the food industry must be encouraged to promote healthy diets in accordance with national guidelines and international standards. Incentives to practice responsible marketing to support the global strategy are essential. The WHO Regional Office for Europe will provide decision makers with examples of good practice and case studies. Today, in 2014, what is the true impact and efficacy of such claims? What is the follow-up of the practical initiatives of EC? Lastly, what is the social input of the proposals for government's regulations towards healthier food and beverages production? Giants of the industry selling foods and drinks have major difficulties to follow policymakers and to adopt voluntary guidelines to provide safer products. Moreover, all industries building products leading to inactivity (cars, screen-based entertainments etc.) must also be involved in the global struggle against overweight and obesity.

Since obesity care varies noticeably across European regions, efforts have been engaged. The efficacy of long-term weight management remains a debated question in the USA [40-42]. To achieve a long-term weight loss and reduction in cardiometabolic health risks is an uneasy task and requires intensive lifestyle interventions which are usually costly and time demanding. The European Association for the Study of Obesity (EASO) has developed a broad network of specialized obesity centers (i.e., EASO Collaborating Centers for Obesity Management (COMS)). Various detailed recommendations for an improvement of the management of obesity in adults [1] and in children [5] have been proposed by the EASO specialized task forces. They aimed to provide simple and practical approaches for the assessment and also the management of overweight and obese children and/or adults. Unsatisfactory results in weight management may represent one of the reasons why physicians, particularly general practitioners, are discouraged from the treatment of obese patients. The creation of networks of care is highly recommended. To obtain optimized efficacy, the association of the general practitioner with other experts, such as obesity specialists, nutritionists 
Lafontan et al.: Opportunities for Intervention Strategies for Weight Management:

Global Actions on Fluid Intake Patterns

or dieticians, exercise physiologists and behavioral therapists (psychologists/psychiatrists), is highly encouraged [43]. To reach the populations in an efficient manner, it is important to implement practical guidelines on healthy lifestyle at the local level in every city. In addition, at worksites, facilitation and promotion of the practice of physical activity must be encouraged whenever possible.

Increasing evidence confirms that food and beverage advertising affects children's food choices and intake. Scientific peer-reviewed papers have reported that advertising for less healthy foods and beverages continue to be found in different countries worldwide. A tendency to shift the market pressure for energy-dense products into countries with fragile and less regulated environments remains common practice. The majority of soft drink sales are outside North America and Europe. The rate of increase of these sales is highest in low- and middle-income countries. It is quite obvious that 'adherence to voluntary codes may not sufficiently reduce the advertising of foods which undermine healthy diets, or reduce children's exposure to this advertising' $[44,45]$. Taxing SSBs has been proposed in high-income countries to reduce obesity and type 2 diabetes. Differences in country-specific contexts create uncertainties in its possible outcomes. It was subjected that SSB and soft drink taxation policy may be more effective in reducing obesity prevalence where existing obesity prevalence and soft drink consumption levels are high [46]. Apparently SSB drink taxes influence BMI but the impact is suggested small in magnitude, at least in the USA [47]. These results are influenced by a very strong lobby seeking to undermine the message as shown in television documentaries. By contrast other researchers from USA support SSB tax taking into account other available scientific evidence [48]. Although the effect is suggested small, we should have in mind that a reduction of $131 \mathrm{kcal} /$ day over a period of 10 years would have reversed the 0.43 $\mathrm{kg} /$ year weight gain among children aged 2-7 years [49]. Estimate of the potential health effects of such a fiscal strategy in the middle-income country of India was recently detailed. It was noted that when they reduce consumption of SSBs, consumers were found to have a tendency to increase net intake of calories from other drinks [50]. An econometric and comparative assessment risk modeling study performed in the UK has led to the conclusion that a $20 \%$ tax on SSBs would lead to a reduction in the prevalence of obesity of $1.3 \%$ (around 180,000 people). The greater effects may occur in young people [51]. Introduced energy drinks taxes in France and Hungary have not been yet evaluated to obtain measurable health impacts. Governments and food industries should work together to reduce the price of healthy food and beverages. Socioeconomically disadvantaged countries and populations will particularly benefit of such decisions.

\section{Specific Policies for Beverages Must Be Improved}

\section{Impact of SSB Consumption on the Obesity Epidemic}

Evidence exists for immediate action concerning SSBs [52-54]. Is it sufficient to convince the populations concerned by SSB consumption? Will reducing SSB consumption reduce obesity? Some groups, often supported by sugar industries and soft drink associations, continue to feed the controversies and scientific debate [55]. According to some authors, evidence supporting conjecture is strong, but evidence when testing effect is weak [56]. In fact, studies funded by industries are less likely to find associations than studies funded from elsewhere [55-58]. Financial conflicts of interest may bias conclusions from published systematic reviews on SSB consumption and weight gain or obesity [59]. 'Sweetened beverages' refer to soft drinks, sport drinks, fruit drinks and SSBs. US children and adolescents today derive 10-15\% of total calories from SSBs and 100\% fruit juice; increasing consumption is observed in all ages [49]. There is epidemiological evidence that SSB 
Lafontan et al.: Opportunities for Intervention Strategies for Weight Management: Global Actions on Fluid Intake Patterns

consumption increases the risk of overweight, obesity, and type 2 diabetes. Consumption is progressing regularly around the world and, at all ages, the cardiometabolic effects from excessive consumption are profound [52]. Results from cross-sectional studies and prospective studies with long follow-up have shown a positive association between excess SSB intake and weight gain and obesity in both children and adults [60]. A recent crosssectional analysis clearly showed that consumers of SSBs were more likely to display metabolic abnormalities compared to non-consumers in a dose-dependent manner [61]. Similarly, in a prospective study of Spanish university graduates an increase in SSB consumption was associated with a higher risk of developing metabolic syndrome and other metabolic disorders [62]. A meta-analysis including 5 experimental and 14 prospective studies concluded that consumption of soft drinks was a determinant of obesity [63]. The last published metaanalysis on this topic achieved the same conclusion [64]. Putative relationships between SSB intake and genetic risk of obesity were recently studied in three separate cohorts of men and women [65]. A recent report has shown that SSB consumption in adolescence and changes in SSB consumption from childhood to adolescence are both significant predictors of change in body fatness later in early adulthood [66]. The specific effect of SSBs on body weight/obesity is still not completely understood but SSBs increase body weight/fat mass though not to a significant degree in all studies [67]. However, exposure to high fructose during critical periods of development of the fetus, neonate, and infant is suspected to be obesogenic. Lifelong alterations of neuroendocrine pathways, appetite control, feeding behavior, adipogenic processes, distribution of fat deposits, and metabolic systems have been reported [68].

Despite promising initial results, studies remain necessary to investigate the mechanism, linking a high consumption of calorically sweetened beverages to subsequent development of overweight and obesity. Apparently, persons exhibiting a predisposition to obesity (e.g., defined with a genetic predisposition score calculated on the basis of $32 \mathrm{BMI}$-associated loci) seem to be more specifically susceptible to the effects of SSBs on BMI [65]. Noteworthy differences in SSB consumption exist between countries and ethnic groups [37] and could explain discrepancies existing between some findings reported by various international groups. As an example, children in the USA consume on average almost three times as many calories from SSBs as the amount reported in a study performed in the normal-weight Dutch children population [69]. Nevertheless, SSB consumption has also been identified as a risk factor for obesity in several European prospective and intervention studies [69-74]. Most American adults consume more added sugar than is recommended for a healthy diet, and a significant relationship was observed between added sugar consumption and increased risk of mortality from cardiovascular diseases [75]. Despite numerous claims and guidelines from health authorities, most American adults were not aware of the actual kilocalorie content of SSBs. It is unclear if health education on the energy content (i.e., calorie content) of SSBs may be beneficial or if some new education tricks must be discovered and extended. Longitudinal studies are still needed to explore associations between knowledge about energy provided by SSBs and SSB intake [76]. A so-called 'well tolerated' intake of SSBs is not determined. Accordingly, intake of SSBs should generally be reduced as much as possible to improve the health of the population.

\section{The Shifts from SSBs to Other Beverages and Water Consumption}

The debate about the benefit of a shift from SSB consumption to low-calorie sweeteners or water intake remains largely open. Referring to the fact that liking for sweetness is an innate human trait that exists from birth, a number of scientists, often supported by industry, proposed to replace sucrose and/or fructose contained in SSBs by non-nutritive sweeteners (NNS). NNS are also told low-calorie or non-caloric sweeteners. Five of these agents are considered as food additives by the Food and Drug Administration (FDA) (i.e., saccharin, sucralose, aspartame, acesulfame- $\mathrm{K}$, and neotame). Stevia is the latest and considered as a 
Lafontan et al.: Opportunities for Intervention Strategies for Weight Management: Global Actions on Fluid Intake Patterns

'natural' sweetener [77]. The tendency to shift from SSB consumption to NNS beverage consumption was heavily supported by the scientific community although the potential role of NNS in facilitating reduction of added sugar intake is far from being evident. Consumers have raised concerns about the taste of some NNS which led to the development of multiple new NNS products and claims about NNS being 'real' sugar (such as sucralose) or 'natural' (such as Stevia). Nevertheless, NNS intake is quite common before any shift to dietary water alone (tap water when accessible or bottled water when tap water is contaminated). Adults are higher consumers of NNS-supplemented beverages than children or adolescents [78]. The consumption of NNS has been associated with protection against weight gain over time [79]. Short-term randomized controlled trials have shown NNS use to be BMI neutral or to have modest weight-reducing effects in overweight and obese adolescents [80-82] and adults [78, 83]. Several meta-analyses have shown that NNS do not have unwanted effects on appetite or subsequent food intake, blood pressure, insulin release, and glucose homeostasis (for review see $[77,84])$. Although some adverse effects of aspartame have been claimed, the European Food Safety authority (EFSA) has concluded that the claims of various opponents were not supported by actual knowledge [85]. Most of the authors of these safety claims forget to ask another essential question. Is there a true usefulness of such food additives in water? What are the true health benefits, if any, of inclusion of aspartame (and other more recent NNS) in beverages [86]? Is it the only reasonable strategy to induce a modest reduction of the intake of calories? It is expected that future quantitative risk-benefit analyses, performed by truly independent scientists, will be able to provide more comprehensive advice. Their long-term effects on children' and adolescents' health are still unknown. Little is known about their mechanisms of action, and some results suggested a putative impact on sweet taste receptors in the gut. Some animal studies have revealed that NNS activate gut sweet-taste pathways that control incretin release and up-regulate glucose transporters. Nevertheless, human studies found that interaction of NNS with sweet-taste gut receptors is not sufficient to elicit incretin responses [87]. The potential benefits of NNS consumption remains a matter of debate. It is suggested that NNS, when rapidly prescribed by clinicians in overweight and obese patients, would facilitate reductions of added sugars but the potential benefits of their intake remain open. Recent studies have shown that dietary changes can reshape the gut microbial community [88-90]. The possible disturbance in host-macrobiota interactions by NNS intake is an open question which requires deeper investigation [91]. It must be questioned if NNS consumption may cause dysbiosis with loss of microbial and genetic diversity of the human gut microbiome.

\section{Beneficial Effects of Dietary Water Intake on Weight}

The association of contributors of water intake with dietary characteristics, meal consumption, and body weight were examined in the US population. Various contributors of total water intake differed in their association with dietary characteristics and body weight in the adult [92]. According to two recent systematic reviews, although limited to nonexhaustive search strategies on weight regulation procedures, it was concluded that increased water consumption may have a beneficial role in weight management and obesity prevention. Encouraging water consumption to substitute energy-containing beverages may facilitate weight management [93, 94]. According to Daniels et al. [95], clinical trials, along with epidemiologic and intervention studies, provide findings which suggest that water has a potentially important role to play in reducing energy intake. Nevertheless, results of cross-sectional associations do not necessarily reveal causal effects of increased water consumption on body weight outcomes.

A recent and important systematic review based on an extensive literature search has summarized the existing evidence on the association between water consumption and body 
Lafontan et al.: Opportunities for Intervention Strategies for Weight Management: Global Actions on Fluid Intake Patterns

weight outcomes in adult of any body weight status. The final outcomes of longitudinal studies with variable follow-up periods and cross-sectional studies were carefully analyzed by the authors [96]. They mentioned that their final conclusions are certainly limited by the paucity of original studies and the limited number of longer-term investigations. Moreover, they performed a careful consideration of the funding of studies to support their interpretations. In the context of studies evaluating the relationship between water consumption and body weight, they did not find any trend for bias by sponsorship. Public health efforts to promote healthy beverages should recognize the potential impact of tap water perceptions on water and SSB intake among low-income populations at higher obesity risk. Understanding characteristics associated with low drinking water intake may help to identify populations that could benefit from targeted and adapted interventions [97].

In two recent studies, changes in water and beverage intake and long-term weight modifications have been investigated in three prospective cohort studies. Increasing water intake instead of SSBs or fruit juices was associated with lower long-term weight gain [98]. In a study (18-month duration) with a double blind design, performed in healthy normal-weight Dutch children, it was shown that masked replacement of a sugar-containing beverage with a sugarfree beverage significantly reduced weight gain and body fat gain [69]. Intervention studies must be oriented towards families since it was noted, at least in US schools but also in EC schools, that they are a rather limited source for SSB consumption [49]. A pilot study in the Netherlands reported that the mean intake of SSBs at school was high, more than $500 \mathrm{ml} /$ day for boys and more than $250 \mathrm{ml} /$ day for girls, but only a minority of these quantities was purchased at school. Moreover, placement of water coolers in a small-scale pilot study did not affect sales of SSBs at schools [99]. Thus, initiatives to restrict SSB access only limited to schools may have a marginal impact on overall SSB consumption. It is important to establish if, in an attempt to reduce sugar-related caloric intake via SSBs, switching to low-calorie sweeteners is safe and does not impact on total calorie intake.

The potential mechanisms that might contribute to a beneficial effect of dietary water intake on weight maintenance and even weight loss are poorly established and are still a matter of debate. One of the most commonly proposed effects is the suppression of hunger with a concomitant reduction of energy intake. Consuming $500 \mathrm{ml}$ water prior to each main meal leads to greater weight loss than a hypocaloric diet alone in middle-aged and older adults; water ingestion was considered to reduce meal energy intake [93]. Self-monitoring of daily increased water consumption may provide additional weight loss or maintenance benefits [100]. Recent observations suggested that $\mathrm{pH}$ of drinking water could affect the composition of gut microflora, thus leading to an altered autoimmune response [101]. However, according to the authors, since it is currently assumed that the $\mathrm{pH}$ of drinking water may only affect the upper alimentary tract, studies are needed in the future to understand the incidence of the $\mathrm{pH}$ of drinking water on the microflora of the upper alimentary tract and the mechanisms triggering immune modulation by these microbial communities.

Some studies have focused their attention on a putative water drinking-induced thermogenesis. For some authors, it was claimed that it could represent an important and unrecognized component of daily energy expenditure. A study has revealed that drinking only $500 \mathrm{ml}$ of water increased energy expenditure and blood pressure response over the course of 60 min after ingestion in normal-weight and obese men and women. Thus, drinking $2 \mathrm{l}$ of water per day would augment energy expenditure by approximately $400 \mathrm{~kJ}$. The water-induced increase in energy expenditure was diminished by a systemic beta-adrenergic receptor blockade. Involvement of sympathetic nervous system activation at the spinal level was suspected [102]. Rather than water temperature or gastrointestinal stretch, involvement of osmosensitive mechanisms or osmolality of water was proposed [103]. It was shown that the osmopressor response to water may be mediated through osmosensitive afferent structures 
Lafontan et al.: Opportunities for Intervention Strategies for Weight Management:

Global Actions on Fluid Intake Patterns

in the gastrointestinal tract, portal vein, and liver [104]. More recently it was demonstrated that the osmopressor response involves the osmosensitive transient receptor potential vanilloid 4 channel (Trpv4) $[105,106]$. Another study has also revealed an increase of up to $25 \%$ in resting energy expenditure following the drinking of $10 \mathrm{ml} / \mathrm{kg}$ of cold water in overweight children, (an effect lasting for over $40 \mathrm{~min}$ ) [107]. From these studies it was suggested that water drinking could assist overweight children in weight loss or maintenance. However, doubt on the importance of the thermogenic effects of water intake also came from other studies. Drinking water that had been cooled to $3^{\circ} \mathrm{C}$ caused a small increase in energy expenditure of $4.5 \%$ over $60 \mathrm{~min}$; it is a minor effect [108]. For other authors, the increase of energy expenditure induced by water load did not exceed the energetic cost of water heating, from room to body temperature [109]. Thus, the true impact of water intake on energy expenditure remains largely an open question and requires further investigations.

Another beneficial physiological mechanism able to explain the impact of water consumption on weight could also be related to the fact that water could be ingested in other forms than plain water and included, for example, in the preparation of hot beverages such as coffee and tea. Water consumed in the form of such non-caloric beverages could exhibit some actions on weight maintenance via caffeine, theophylline, and the numerous polyphenols. Caffeine and related methylxanthines are perceived as substances having both a diuretic action and a lipolytic effect. However, diuretic effects are observed after the ingestion of coffee and tea only in large doses and by individuals who have been deprived of caffeine for a couple of days. However, consumption of caffeine-containing beverages does not lead to fluid loss and is not associated with poor hydration status. It is considered that a tolerance to diuretic effects of caffeine develops in regular consumers of coffee or tea. Its diuretic action cannot be demonstrated in such consumers [110]. Tea consumption is inversely associated with weight status and other markers of the metabolic syndrome [111]. Green tea preparations, which contain both catechins and caffeine, are believed to have thermogenic and antiobesity properties. Consumption of green tea preparations when combined with resistance training increases body fat loss, waist circumference reduction, lean body mass and muscle strength, and reduces triacylglyceride levels [112]. Of note, in recent years, due to aggressive and questionable marketing strategies of beverage industry towards young population, the consumption of sport drinks and also energy drinks has become popular for young adults in North America, Europe, and a number of other countries. They have a tendency to replace SSBs, even in a population with limited physical activity.

Despite the increasing number of reported studies addressing the weight gain prevention or weight-reducing effects of increased water consumption that raise awareness among members of the public health community, evidence for an association is still low, mostly because of the lack of good-quality studies which are expected in the near future [96]. Tap water is accessible and safe in many countries, but its relevance for the public health remains debated. Unfortunately, studies on tap water have not been proposed by the time being by any public health authority or government. Most of studies on water consumption were funded by the beverage industries which are interested in marketing bottled water. Nevertheless, in the context of obesity prevention and hydration it seems obviously safer to promote the consumption of water instead of SSBs from a Public Health perspective.

\section{Actualized Guidelines for Fluid Intake}

The importance of the nature of fluid intake has been often neglected in guidelines and also in the clinical setting. Fluid intake recommendations are difficult to establish and must take into account variations due to work and physical exercise intensity, environmental conditions, and even protective clothing. A number of recent reviews about the physiological regulation of body fluids, thirst, and fluid intake have been published [113-116]. It is unclear 
Lafontan et al.: Opportunities for Intervention Strategies for Weight Management: Global Actions on Fluid Intake Patterns

why humans do not appear to react to the physiological signs of thirst as animals. Voluntary drinking is also a behavior influenced by numerous social and psychological cues; several factors have been discussed $[115,117]$. Practically, the question 'what do you drink' is often omitted in the usual questionnaires, and recommendations for beverage (fluid) volumes intake are absent of most 'food pyramids'. The need for an improved healthy hydration must be highlighted in public health. This overview does not intend to systematically review all the numerouspapersand systematicreviews concerningwaterconsumption, weightmanagement, and obesity prevention.

The recommendation 'drink to thirst' is frequently given to healthy individuals during daily life. However, factors and conditions (e.g., age and disease) that influence thirst should be recognized and probed further. Perceived thirst and ad libitum drinking are not equivalent measures of human thirst [115]. Human water needs have often been discussed [118-120], and recommendations for healthier hydration have recently been proposed [121]. In this paper, the authors claim that attention of providers of healthcare education and the public must be alerted and must be aware of important points:

- Overconsumption of SSBs and other beverages containing sweeteners exert detrimental effects on long-term health.

- The composition and sugar content (with calorie equivalents) of actual and emerging beverages is regularly modified for marketing purposes and difficult to follow by the consumers; a clearer labeling of beverages is needed. iii).

- It is important to favor healthy hydration in community intervention programs to obtain data that will assess the role of water consumption in a healthy and balanced diet.

Several actions were proposed at a local, but also national level to ensure adoption by the general public [121]. The following proposals focus attention on various aspects related to water consumption:

- Revision of national nutrition guidelines to emphasize the importance of water as a macronutrient and to include dietary water within the 'food pyramids' around the world. EC countries have the chance to have an access to safe tap water; the cheaper beverage available for all. It is an important point to remind to the EC consumers. However, a number of countries still have no access to safe water.

- Inclusion of practical advices will facilitate healthy hydration behavior within the context of the rapid evolution of dietary and lifestyle changes and the regular emergence of heavily marketed beverages of questionable value for health. Special attention must be paid to the low-income populations and populations which are the most susceptible to develop obesity. Early preschool programs must be developed for young children.

- Guidelines should be simple, effective, and include easy-to-remember targets for each group of individuals (table 1). For example, according to EFSA, guidelines advise normal adults to consume approximately $2 \mathrm{l}$ of total water per day for females and $2.5 \mathrm{l}$ for males. Daily total water needs increase with age from early infancy (0.85-1.0 l/day) between 6 to 12 months through childhood with $2.1 \mathrm{l}$ /day for boys and $1.9 \mathrm{l}$ /day for girls from 9 to 13 years of age [122]. There is a need to emphasize the consumption of safe water intake during the practice of physical activity and sweating and for all those living in hot environments; adaptations of the general recommendations could become necessary. Importantly, healthy eating behaviors and regular exercise practice must be associated to the hydration guidelines.

- Validation and optimization of the usual hydration procedures by longitudinal studies extended to different populations with water being the primary research question in the exploration between body weight outcomes and water intake (different countries, different environments, different socioeconomic levels, and different age groups affected by various diseases and patients submitted to medications). New research programs 
Lafontan et al.: Opportunities for Intervention Strategies for Weight Management: Global Actions on Fluid Intake Patterns

Table 1. Summary of human water needs

- Water is an essential macronutrient; the major routes for water output from the body are kidneys, skin and respiratory tree. It is considered that a sedentary adult loses between 2.0-3.0 l of water per day.

- Contribution of food to total water intake is $20-40 \%$ whereas $60-80 \%$ are provided by beverages. This relationship is quite variable and largely depends on the choice of foods and beverages in the countries.

- Establishment of water reference intakes is conditioned by habits of the population (food and beverages habits). Ideally, the best recommendations set up must be by country or continent.

- $\quad$ The adequate intake (AI) of water is derived from intake levels experimentally defined to meet adequacy for all members of the reference healthy population.

- Daily total water needs increase with age from early infancy (0.85-1.0 l/day) between 6 to 12 months through childhood with $2.1 \mathrm{l}$ /day for boys and $1.9 \mathrm{l}$ /day for girls from 9-13 years of age. Adolescents of 14 years and older are considered as adults. (EFSA guidelines, 2010).

- For adults, according to EFSA guidelines, the median total daily water needs for sedentary individuals living in temperate climates approach $2.5 \mathrm{l}$ for men and $2.0 \mathrm{l}$ for women (which must be adjusted to 2.3 liters during pregnancy and $2.7 \mathrm{l}$ during lactation). Note that a sweat loss induced by modest daily exercise could reach $1.4 \mathrm{l} /$ day and increase daily water requirements by $45 \%$.

- Elderly individuals are at higher risk of developing dehydration for various physiological reasons. Loss of physical and mental autonomy aggravates the capacity to drink. It is considered that the minimum water intakes for drinking water and beverages must range from 1.5-1.8 l/day; some adaptations are often done according to the age, sex and medications.

- When exercising, water is the best drink for most people, most of the time. Water is sufficient for low to moderate-intensity physical exercise. Non-endurance athletes do not need to immediately replace carbohydrate or sodium loss from sweating. Cold water is fine for rehydration. Fruit juices and soda should be avoided since they contain too much sugar.

- Athletes enduring physical activity for more than $90 \mathrm{~min}$ at a time, sports drinks and adapted fluid-replacement beverages offer beneficial interest to partly replenish water loss and lost nutrients.

- $\quad$ Caffeine, which is present in coffee, tea, chocolate, and numerous 'energy drinks' has a diuretic and natriuretic effect. It decreases water and particularly sodium reabsorption in the kidney and can potentially lead to a total body water deficit .

- When exercising in a hot environment, sweating can reach 1 or $2 \mathrm{l} / \mathrm{h}$ of water loss. Water losses incurred under extreme conditions implicating external temperature and heavy physical exercise, water losses can be up to about $8.0 \mathrm{l}$ /day and must be replaced with appropriate amounts of water (and electrolytes).

should be initiated to identify the specific daily water needs of groups at risk of disturbed hydration (e.g., patients treated with laxatives or diuretics resulting in sodium loss, sedentary and/or active children, pregnant and lactating women etc.). Water intake recommendations are often based on the assumption that solid food and metabolic water could provide $1 \mathrm{l}$ of water daily; more precise evaluations could be necessary in some individuals. This relationship is quite variable and largely depends on the choice of foods and beverages in the countries. Safe hydration remain a major challenge in a number of countries facing major problems for a free access to safe tap water and spring-water without any bacterial or chemical contaminations.

- Elderly individuals are at increased risk losing water compared with younger adults since ageing affects several parameters of water metabolism (i.e., diminution of liquid intake and increase in liquid losses). The total water intake for the middle-old and oldestold was significantly lower than that for the young-old [123, 124]. Moreover, solid food may not provide sufficient daily water in the elderly as in adults. Hypohydration is 
Lafontan et al.: Opportunities for Intervention Strategies for Weight Management: Global Actions on Fluid Intake Patterns

considered as a precipitating factor in a number of acute medical problems in elderly. The increased risk of dehydration is related to several factors such as the decreased efficacy of kidney to concentrate urine and its relative resistance to vasopressin (the anti-diuretic hormone) action, the lowered secretion of aldosterone, the decrease of renin activity, and, finally, the decrease of the sensation of thirst. Hydration care of older people must also take in account difficulties in gaining access to drinks with diminution of mobility, cognitive alterations, swallowing problems, or visual troubles. Strategies for ensuring good hydration in the elderly have been proposed $[125,126]$. Recommendations from different nutrition societies are quite heterogeneous. Optimal hydration conditions are debated, a minimum of 700-800 ml/day was usually recommended for the oldest individuals by some authors [125]. The minimum water intake for drinking water and beverages for elderly > 65 years must range from 1.5 to $1.8 \mathrm{l}$ /day for others; some adaptations being necessary according to the age and sex [123].

- A need for appropriate water intake definition is requested in populations living under very hot climate or when working hard under warm environmental conditions. Thermoregulatory sweat is the main source of water loss, and evaporation of sweat is the main avenue of heat loss during exercise and heat stress. Under such extreme conditions sweating can reach 1 or $2 \mathrm{l} / \mathrm{h}$ of water loss and water losses can be up to about $8.0 \mathrm{l} /$ day and must be replaced with appropriate amounts of water. Moreover hydration and nutrition of individuals engaged in distance events, ultra endurance exercise, and adventure racing also require special attention [127].

\section{Physical Activity Counseling in Weight Loss and Weight Maintenance}

\section{Rationale for the Role of Exercise in Weight Loss and Weight Maintenance}

Mechanization has reduced hard physical labor as well as physically active transportation. Physical activity and exercise are components of energy expenditure and therefore of energy balance. Resting metabolic rate represents the major component of total energy expenditure. A number of studies have investigated the evolution of energy expenditure and physical activity and discussed their influence on obesity risk. Body weight normally increases with age, but habitual, lifetime physical activity can reduce weight gain. Roughly, the most likely environmental factor contributing to the current obesity epidemic is the continued decline in daily energy expenditure which is not matched by an equivalent reduction in energy intake $[128,129]$. However, it has also been suggested that the increased energy supply in the USA is more than sufficient to explain the epidemic of obesity in this country [130]. Participation in appropriate amounts of activity can support healthy weight maintenance or even weight loss. Sitting time appears to be an independent risk factor for the development of metabolic risk factors; persons who spend more time sitting and watching television have worse metabolic profiles [131, 132]. Some authors claim that evidence does not support a relationship between physical activity and obesity and have a tendency to minimize the role of physical activity [133]. It is certain that the causes of the obesity epidemic which are poorly understood facilitate emerging contradictory debates [134]. Nevertheless, it is generally accepted that moderately active persons gain less weight over time than sedentary people. A strong recommendation needs to be made to improve interventions that promote physical activity within the context of behavioral weight loss interventions [135]. Maintaining high activity levels through young adulthood may lessen weight gain during young adult's transition to middle age, particularly in women $[136,137]$. Inversely, a recent study has shown that short-term positive energy balance from overfeeding and under-activity resulted in impaired metabolic outcomes and alterations in the expression of several key genes involved 
Lafontan et al.: Opportunities for Intervention Strategies for Weight Management: Global Actions on Fluid Intake Patterns

in nutritional balance, metabolism, and insulin action within adipose tissue. These changes were mostly prevented by the addition of a daily vigorous-intensity exercise bout even in the face of a standardized energy surplus [138]. Declines in physical activity contribute to the obesity epidemic. For example, studies over 5 decades have shown that a decrement of daily occupation-related energy expenditure which has decreased by more than $100 \mathrm{cal} /$ day may have contributed to the increasing prevalence of obesity in women during the last 5 decades $[139,140]$. Improved methods for calculating population-level estimated energy requirements and average physical activity ratio will certainly provide novel quantitative baseline values for future investigations into associations of physical activity and health [141]. Moreover, in front of the potential intergenerational transmission of obesity and obesogenic behaviors, it was recently suggested that maternal inactivity may be an important target for the primary prevention of chronic non-communicable diseases and obesity [142]. To summarize, exercise is essential for the prevention of weight gain over the life span, although the amount required to prevent weight gain is difficult to determine properly. According to American authors, it may be closer to twice the amount of exercise recommended by the current Physical Activity Guidelines for Americans [143].

\section{Physical Activity and Adipose Tissue}

Physical activity influences adipose tissue both acutely and in the longer term. Changes in energy balance alter fat mass. Epidemiological observations support the idea that physically active people have relatively low fat mass. A single bout of exercise stimulates adipose tissue blood flow and fat mobilization, resulting in delivery of fatty acids to skeletal muscles at a rate well-matched to metabolic requirements. Metabolic efficacy is an important parameter which could affect weight loss in response to a physical activity intervention. Differences in metabolic adaptation (i.e., in the decrease in energy expenditure that occurs with weight loss) have been reported. One study was devoted to the comparison of ethnic differences in the reduction in energy expenditure in response to a weight loss program [144]. The diversity of immigrant populations in European countries is continuously increasing, and more studies are necessary to understand why the impact of physical activity on weight maintenance and cardiometabolic risk differs according to ethnicity. The best approaches to promote physical activity in nonCaucasians ethnic groups are still to be established [145].

Intervention studies tend to show that exercise training reduces fat mass. A recent review has explored the role of physical activity and exercise training in the prevention of weight gain, initial weight loss, and weight maintenance. The discussion was oriented towards the expected initial weight loss from different exercise training programs and has explored their intensity/volume relationships. [146]. A single bout of exercise stimulates adipose tissue blood flow and fat mobilization, resulting in delivery of fatty acids to skeletal muscles. In addition to the regulation of fat mass, physical activity may contribute to metabolic health through beneficial dynamic changes within adipose tissue in response to each activity bout. Recent reviews have examined the impact of physical activity on visceral fat. Briefly, out of 17 randomized controlled studies that reported only modest weight loss with an exercise intervention $(>3 \%)$, the vast majority reported significantly reduced visceral adipose tissue $[147,148]$. A much discussed effect of exercise versus calorie restriction in preferentially reducing visceral fat is not borne out by meta-analyses.

In weight loss programs, exercise training has been shown to optimize fat loss when associated to energy restriction. Nevertheless, aerobic exercise training programs consistent with public health recommendations may promote up to modest weight loss $(\sim 2 \mathrm{~kg})$. The weight loss on an individual level is highly heterogeneous, and clinicians should educate their patients on this point. One needs to have reasonable expectations about weight loss through a physical activity program and should remember that health benefits could occur in the absence or 
Lafontan et al.: Opportunities for Intervention Strategies for Weight Management:

Global Actions on Fluid Intake Patterns

with minimal weight loss [146]. A preferential loss of visceral fat, which has been reported during long-term follow-up, could bring health benefits without striking weight changes. Light physical activity, determined by a motion sensor device, reduces visceral fat and decreases insulin resistance in high-risk subjects [149]. Aerobic exercise, but not resistance exercise, reduce visceral fat and improve insulin sensitivity in obese adolescent girls [150]. The health benefits of resistance training should not be undervalued. Increased intensity in high-volume training is efficient in enhancing visceral fat loss in moderately obese individuals. High-intensity-resistance training induces faster visceral fat loss [151]. Evaluation of changes in fat mass and lean mass are recommended in determining the impact of exercise on body weight. During weight loss programs, gender-related differences have been reported in the increased calorie intake following exercise. Women have a tendency to compensate by increasing energy intake after exercise [153]. Prescription of exercise training requires appropriate definition of the length of the prescribed bouts of aerobic versus resistance training for the individuals. Aerobic alone and aerobic plus resistance training significantly improved metabolic syndrome scores and prevalence in patients with type 2 diabetes [153].

Claims of the benefits of physical activity and physical activity guidelines exist in many countries [154-156]. In pre-pubertal obese children, a regular physical activity program reduces blood pressure, arterial stiffness and abdominal fat, and increases cardiorespiratory fitness. Moreover, arterial wall remodeling is delayed [157]. The major problem is to reach the physical activity goals as clearly described in the guidelines. It is essential to convince the overweight and obese patients that individuals who are physically active have fewer visits to the physician, shorter stays in the hospital, and a reduced medication. Adults should be encouraged to reduce the time spent in sedentary behaviors, whenever possible, and to participate in moderate to vigorous physical activity at recommended levels [132]. Exercise training is beneficial for weight loss if the exercise program is strictly followed by the individuals. Trained experts of physical activity and exercise protocols must be the prescribers of exercise programs. Exercise is like a medical protocol with a definition of indication, dosage, and putative side effects which requires guidance to settle the appropriate progression of aerobic activity/strength training adapted to the weight status of the patients and to the existing comorbidities [148]. Moreover, it is important to keep in mind that exercise recommendations are often difficult to complete for individuals who are already overweight or obese. If body composition is determined, it provides an excellent tool to explain to the patients the benefits of physical activity, independently of body weight changes. The resistance of some fat deposits to exercise-induced lipid mobilization could be disappointing for some patients $[158,159]$. Such limitations must be communicated by the practitioner to clearly explain the benefits but also some limits of exercise.

\section{Exercise and Hydration}

Loss of body fluids containing water and electrolytes during exercise occurs mostly by sweating. Sweat rates will vary according to a number of factors, including the size of the athlete and his or her degree of acclimatization, environmental conditions, the intensity of exercise, and the clothing worn [160]. Individuals who participate regularly in recreational sports and/or exercise are dehydrated during exercise and drink at a rate according to their perceived thirst, which barely replaces two thirds of their fluid losses [161]. Mechanisms of aerobic performance impairment with heat stress and dehydration have been investigated [162]. When possible, fluid should be ingested at rates that most closely match sweating rate [163]. Practical recommendations were published recently [122]. Papers have reported that ingestion of carbohydrates before or during exercise result in a marked reduction in fatty acid oxidation while drinking water results in better fat oxidation rates during exercise performed at $<70 \% \mathrm{VO}_{2} \max [117,164]$. 
Lafontan et al.: Opportunities for Intervention Strategies for Weight Management: Global Actions on Fluid Intake Patterns

In recent years, the consumption of sport drinks and energy drinks, a rapidly growing segment of beverage industry, has become popular among adolescents and young adults performing physical activity in North America, Japan, and Europe. Sport drinks contain, in addition to their sugar content, electrolytes, minerals, and vitamins. They are often caffeinated beverages that intend to enhance alertness and 'boost' performance. The content of sodium is less desired in subjects with hypertension, whereas contents of calcium and magnesium are welcome. The basic stimulant ingredient in energy drinks is caffeine (a typical energy drink can contain up to $80 \mathrm{mg}$ of caffeine), although they may or may not include high doses of sugar (or a sugar substitute). They generally include various ingredients including B vitamins, an amino acid (e.g., taurine or l-carnitine), and plant/herbal extracts (e.g., ginseng, ephedrine, milk thistle, Ginkgo biloba, or Guarana seeds extracts). Outside the well-known actions of caffeine [165], the potential benefits or deleterious effects of the other ingredients contained in energy drinks remains to be determined. The increased popularity of energy drinks among adolescents and young adults is not surprising given the aggressive and questionable marketing strategies towards this population. Most of them are endorsed by celebrities. Despite their increasing popularity among adolescents and young adults, as revealed by a recent US survey [166], it is important to mention that their intake is not needed for a large proportion of active individuals performing moderate exercise. Adverse events and harmful side effects have been reported with energy drink intake, and individuals with cardiovascular, metabolic, neurological, hepatic or renal diseases should avoid their use before approval of a medical expert [167].

While sport drinks are widely available for business purposes, they are only really helpful to a small minority of athletes [116]. Intake of sport drinks is not necessary for anybody exercising less than $90 \mathrm{~min}$. Water intake is largely sufficient for normal hydration. The vast majority of physically active individuals do not exercise hard enough to need the childattractive colorful drinks. An average period of exercise does not deplete the body enough to require additional energy and electrolytes; water intake is largely sufficient. The body is very efficient at providing/compensating itself to fuel a moderate exercise period. $80-85 \%$ of an active population does not get enough exercise to need sport drink intake. Among the remaining $15-20 \%$ that do exercise, $1-5 \%$ are exercising really hardly and intensely enough to really need fluid replacement beverages. During intense cycling, it would take about $2 \mathrm{~h}$ of strenuous activity before benefits from the sugar and electrolytes contained in sport drinks could be useful. It is certain they could also be useful when exercising intensely in the heat and for a very long time period. Interest and limits of sport and energy drink utilization requires deeper investigations [116].

Lastly, among the strategies aiming at improvement of daily physical activity, utilization of public transportation merit deeper attention and recommendation. Populations from Australia and countries of North America are highly car-dependent when compared with European countries, which have less obesity and which have higher rates of walking and cycling. Walking and cycling for transport are directly related to improved health of older adults [168]. Using public transportation encourages people to be more active than if they are using their personal cars. They are more active generally by walking and standing up. Multidisciplinary research on environmental contributions to physical activity levels in the population must be developed to examine the impact of built environment, neighborhood, and other physical environment factors on physical activity practices [169-171]. Many studies have clearly provided evidence of the benefit of active travel at the population level. Policies of transport, land use, and the urban development should be designed to encourage, walking and cycling for daily travel [172]. 
Lafontan et al:: Opportunities for Intervention Strategies for Weight Management: Global Actions on Fluid Intake Patterns

\section{Conclusions and Future Trends}

To conclude, it is anticipated that the next 10 years will reveal worldwide the collective ability to limit the extent and impact of obesity. It is essential to curb future obesity and noncommunicable disease epidemics. In a world facing massive demographic, economic, and environmental shifts, the changing levels of poverty and inequality have a negative impact on the obesity pandemics. Despite the innovative biological, physiological, and genetic discoveries that have been made over the last 40 years the pandemic of obesity progresses regularly, particularly in developing countries. There is strong evidence that the prevalence of obesity will be translated into increased mortality and noticeable economic and social damages in the affected populations. Preventing the rapid progression of obesity among children and adolescents is a worldwide major challenge.

Early intervention strategies to improve weight loss (or prevent weight gain) during growth as well as counseling of overweight and obese patients by clinicians should be developed and optimized. All the successful interventions who have demonstrated efficacy need to be used and disseminated at national and regional levels. Efficacy of counseling practice guidelines alone do not appear to elicit appropriate and long-lasting behavioral changes. Public health messages raising awareness on obesity are very weak and fragile when confronted to the powerful advertising potencies of the food industry (i.e., multinational and beverage companies). The Westernized lifestyle is expanding and probably becoming even more obesogenic in countries such as South America, China, Indonesia, India, and African countries. Diets change whenever incomes rise in the developed world. Low- and middle-income countries have a tendency to abandon their traditional nutritional habits. Urbanization in many parts of the world has changed people's eating and drinking habits away from traditional healthy diets.

Processed foods and drinks sold by the food industries are invading the world. Deeper examination of the food industry is necessary; competing views on how public health professionals might engage with food industries have recently been discussed [173]. The rates of soft drink sales by industrial giants are the highest in the developing countries while it is slightly leveling in the Western part of the world. Average energy density of beverages sold decreases in USA while the opposite occurs in the developing markets. Can beverage companies cut calories while maintaining profits [174]? How might public health professionals be able to engage a strong debate with food industries? They should adapt to provide healthy products, their profits being secondary to health in the world. It is essential to examine the activities and influences of the food and beverage industry especially in children and lowsocioeconomic-status populations [173]. The impact of the products they sell induce important costs to public health systems. They progress regularly and a constant evaluation by public health professionals is required. Future challenges probably include the development of different policies [175]. According to some authors, there is no evidence to support the effectiveness or safety of self-regulation of food industries [45]. It is noticeable that sweetened beverage companies, in response to health concerns about their products, have developed multinational corporate social responsibility campaigns that aim to influence government policies and sales increment, with a special interest for young people. The potential effects on public health of reformulating products and reduction of packages and portion sizes needs further evaluation in various countries.

Finally, public health efforts to promote healthy beverages should recognize the potential impact of water intake among low-income populations at higher obesity risk. In the context of obesity prevention and hydration it seems obviously safer to promote the consumption of water from a public health perspective. Tolerable changes in physical activity have been shown to be more effective and lasting than some approaches based on pharmacological treatments. All intervention studies that simulate the actual nature of real-life physical activity 
Lafontan et al.: Opportunities for Intervention Strategies for Weight Management:

Global Actions on Fluid Intake Patterns

must be encouraged. As claimed by Ross and Bradshaw [147] 'clinicians could encourage positive lifestyle changes in their patients by counseling them that obesity and its associated health risks can be reduced in response to an increase in physical activity with or without weight loss'. Information on motives for drinking are still needed before conclusions can be made about ideal drinking strategies for sports. There is considerable variability for water and electrolyte losses between individuals and between the different activities. Hydration practices in sports (i.e., water vs. 'sport' or 'energy' drink consumption) merit experimental validation and certainly deeper attention in front of the numerous claims driven by marketing purposes $[116,160]$. In children, water is the only drink recommended during an effort of less than $1 \mathrm{~h}$ as claimed by the American Academy of Pediatrics. The possible role of the scientific community, in coordination with governments and food industries, to promote healthy lifestyle and limit the promotion of sweetened beverages in youth must be encouraged. Water consumption has a clearly high potential in our aims to combat the obesity epidemic, to improve global health, and to reduce inequalities. The 'pool' of evidence now needs to be 'watered' by studies on whom, when, and where to stimulate drinking water.

\section{Acknowledgements}

The authors thank Susanna Lehtinen-Jacks, Maira Bes-Rastrollo from the EASO Prevention and Public Health Task Force (PPHTF) and the following members of the EASO Obesity Management Task Force (OMTF) for their valuable comments and suggestions: Vojtech Hainer, Hans Hauner, Lisbeth Mathus-Vliegen, Javier Salvador, Yves Schutz, Constantine Tsigos, and Roberto Vettor.

\section{Disclosure Statement}

The authors are members of the EASO Healthy Hydration Working Group. M.L. research activity on obesity-related problems was mainly funded and supported by Inserm (Institut National de la Santé et de la Recherche Médicale), Paul Sabatier University, Toulouse University Hospital and grants from National Research Agency (ANR) and the Commission of the European Communities (EUROLIP Network and FATLINK). M.L. declares to serve as a consultant for the Hydration for Health Initiative (H4H) sponsored by Danone Nutricia Research. Other authors are members of EASO Task Forces: T.L.S.V (Prevention and Public Health), N. F-L (Childhood Obesity) and V. Y. (Obesity Management). The university to which T.L.S.V. belongs is involved in an EU program entitled EPODE for the promotion of Health Equity.

\section{References}

1 Tsigos C, Hainer V, Basdevant A, Finer N, Fried M, Mathus-Vliegen E, Micic D, Maislos M, Roman G, Schutz Y, Toplak H, Zahorska-Markiewicz B: Obesity Management Task Force of the European Association for the Study of Obesity. Management of Obesity in Adults: European Clinical Practice Guidelines. Obes Facts 2008;1:106116.

-2 Sundblom E, Petzold M, Rasmussen F, Callmer E, Lissner L: Childhood overweight and obesity prevalences levelling off in Stockholm but socioeconomic differences persist. Int J Obes (Lond) 2008;32:1525-1530.

-3 Lioret S, Touvier M, Dubuisson C, Dufour A, Calamassi-Tran G, Lafay L, Volatier JL, Maire B: Trends in child overweight rates and energy intake in France from 1999 to 2007:relationships with socioeconomic status. Obesity (Silver Spring). 2009;17:1092-1100.

4 Kautiainen S, Koivisto AM, Koivusilta L, Lintonen T, Virtanen SM, Rimpela A: Sociodemographic factors and a secular trend of adolescent overweight in Finland. Int J Pediatr Obes 2009;4:360-370.

-5 Baker JL, Farpour-Lambert NJ, Nowicka P, Pietrobelli A, Weiss R: Evaluation of the overweight/obese child practical tips for the primary health care provider: recommendations from the Childhood Obesity Task Force of the European Association for the Study of Obesity. Obes Facts 2010;3:131-137.

6 Gutierrez-Fisac JL, Guallar-Castillon P, Leon-Munoz LM, Graciani A, Banegas JR, Rodriguez-Artalejo F: Prevalence of general and abdominal obesity in the adult population of Spain, 2008-2010: the ENRICA study. Obes Rev 2012;13:388-392. 
Lafontan et al.: Opportunities for Intervention Strategies for Weight Management: Global Actions on Fluid Intake Patterns

7 de Wilde JA, van Dommelen P, Middelkoop BJ, Verkerk PH: Trends in overweight and obesity prevalence in Dutch, Turkish, Moroccan and Surinamese South Asian children in the Netherlands. Arch Dis Child 2009;94: 795-800.

8 Speakman JR: Evolutionary perspectives on the obesity epidemic: adaptive, maladaptive, and neutral viewpoints. Annu Rev Nutr 2013;33:289-317.

-9 Odegaard AO, Koh WP, Yuan JM, Gross MD, Pereira MA: Western-style fast food intake and cardiometabolic risk in an Eastern country. Circulation 2012;126:182-188.

10 Pan A, Malik VS, Hu FB: Exporting diabetes mellitus to Asia: the impact of Western-style fast food. Circulation 2012;126:163-165.

11 Magnusson M, Sorensen TI, Olafsdottir S, Lehtinen-Jacks S, Holmen TL, Heitmann BL, Lissner L: Social inequalities in obesity persist in the nordic region despite its relative affluence and equity. Curr Obes Rep 2014;3:1-15.

-12 Keith SW, Redden DT, Katzmarzyk PT, Boggiano MM, Hanlon EC, Benca RM, Ruden D, Pietrobelli A, Barger JL, Fontaine KR, Wang C, Aronne LJ, Wright SM, Baskin M, Dhurandhar NV, Lijoi MC, Grilo CM, DeLuca M, Westfall AO, Allison DB: Putative contributors to the secular increase in obesity: exploring the roads less traveled. Int J Obes (Lond) 2006;30:1585-1594.

13 McAllister EJ, Dhurandhar NV, Keith SW, Aronne LJ, Barger J, Baskin M, Benca RM, Biggio J, Boggiano MM, Eisenmann JC, Elobeid M, Fontaine KR, Gluckman P, Hanlon EC, Katzmarzyk P, Pietrobelli A, Redden DT, Ruden DM, Wang C, Waterland RA, Wright SM, Allison DB: Ten putative contributors to the obesity epidemic. Crit Rev Food Sci Nutr 2009;49:868-913.

14 Misra A, Khurana L: Obesity and the metabolic syndrome in developing countries. J Clin Endocrinol Metab 2008;93(11 suppl 1):S9-30.

15 Danaei G, Ding EL, Mozaffarian D, Taylor B, Rehm J, Murray CJ, Ezzati M: The preventable causes of death in the United States: comparative risk assessment of dietary, lifestyle, and metabolic risk factors. PLoS Med 2009; 6:e1000058.

-16 Finucane MM, Stevens GA, Cowan MJ, Danaei G, Lin JK, Paciorek CJ, Singh GM, Gutierrez HR, Lu Y, Bahalim AN, Farzadfar F, Riley LM, Ezzati M: National, regional, and global trends in body-mass index since 1980:systematic analysis of health examination surveys and epidemiological studies with 960 country-years and 9.1 million participants. Lancet 2011;377:557-567.

17 Malik VS, Willett WC, Hu FB: Global obesity: trends, risk factors and policy implications. Nat Rev Endocrinol 2013;9:13-27.

18 Ogden CL, Carroll MD, Flegal KM: High body mass index for age among US children and adolescents, 20032006. JAMA 2008;299:2401-2405.

19 Brunt H, Lester N, Davies G, Williams R: Childhood overweight and obesity: is the gap closing the wrong way? J Public Health (Oxf) 2008;30:145-152.

20 Visscher TLS, Heitmann BL, Rissanen A, Lahti-Koski M, Lissner L: A break in the obesity epidemic? Explained by biases or misinterpretation of the data. Int J Obes (Lond) 2014; doi: 10.1038/ijo.2014.98.

21 Skinner AC, Skelton JA: Prevalence and trends in obesity and severe obesity among children in the United States, 1999-2012. JAMA Pediatr. 2014;168:561-566.

22 Sonne-Holm S, Sorensen TI, Jensen G, Schnohr P: Influence of fatness, intelligence, education and sociodemographic factors on response rate in a health survey. J Epidemiol Community Health 1989;43:369-374.

-23 Cecchini M, Sassi F, Lauer JA, Lee YY, Guajardo-Barron V, Chisholm D: Tackling of unhealthy diets, physical inactivity, and obesity: health effects and cost-effectiveness. Lancet 2010;376:1775-1784.

24 Swinburn BA, Sacks G, Lo SK, Westerterp KR, Rush EC, Rosenbaum M, Luke A, Schoeller DA, DeLany JP, Butte $\mathrm{NF}$, Ravussin E: Estimating the changes in energy flux that characterize the rise in obesity prevalence. Am J Clin Nutr 2009;89:1723-1728.

25 Knowler WC, Barrett-Connor E, Fowler SE, Hamman RF, Lachin JM, Walker EA, Nathan DM: Reduction in the incidence of type 2 diabetes with lifestyle intervention or metformin. N Engl J Med 2002;346:393-403.

-26 Pan XR, Li GW, Hu YH, Wang JX, Yang WY, An ZX, Hu ZX, Lin J, Xiao JZ, Cao HB, Liu PA, Jiang XG, Jiang YY, Wang JP, Zheng H, Zhang H, Bennett PH, Howard BV: Effects of diet and exercise in preventing NIDDM in people with impaired glucose tolerance. The Da Qing IGT and Diabetes Study. Diabetes Care 1997;20:537-544.

-27 Li G, Zhang P, Wang J, Gregg EW, Yang W, Gong Q, Li H, Jiang Y, An Y, Shuai Y, Zhang B, Zhang J, Thompson TJ, Gerzoff RB, Roglic G, Hu Y, Bennett PH: The long-term effect of lifestyle interventions to prevent diabetes in the China Da Qing Diabetes Prevention Study: a 20-year follow-up study. Lancet 2008;371:1783-1789.

-28 Lindström J, Peltonen M, Eriksson JG, Ilanne-Parikka P, Aunola S, Keinänen-Kiukaanniemi S, Uusitupa M, Tuomilehto J; Finnish Diabetes Prevention Study (DPS): Improved lifestyle and decreased diabetes risk over 13 years: long-term follow-up of the randomized Finnish Diabetes Prevention Study (DPS). Diabetologia 2013; 56:284-293.

-29 Ramachandran A, Snehalatha C, Mary S, Mukesh B, Bhaskar AD, Vijay V: The Indian Diabetes Prevention Programme shows that lifestyle modification and metformin prevent type 2 diabetes in Asian Indian subjects with impaired glucose tolerance (IDPP-1). Diabetologia 2006;49:289-297.

-30 Economos CD, Hyatt RR, Goldberg JP, Must A, Naumova EN, Collins JJ, Nelson ME: A community intervention reduces BMI z-score in children: Shape Up Somerville first year results. Obesity (Silver Spring) 2007;15:13251336.

-31 Gortmaker SL, Peterson K, Wiecha J, Sobol AM, Dixit S, Fox MK, Laird N: Reducing obesity via a school-based interdisciplinary intervention among youth: Planet Health. Arch Pediatr Adolesc Med 1999;153:409-418. 


\begin{tabular}{l|l}
\hline Obes Facts 2015;8:54-76 \\
\hline DOI: $10.1159 / 000375103$ & $\begin{array}{l}\text { C } 2015 \text { S. Karger GmbH, Freiburg } \\
\text { www.karger.com/ofa }\end{array}$ \\
\hline
\end{tabular}

Lafontan et al.: Opportunities for Intervention Strategies for Weight Management:

Global Actions on Fluid Intake Patterns

-32 Pekka P, Pirjo P, Ulla U: Influencing public nutrition for non-communicable disease prevention: from community intervention to national programme - experiences from Finland. Public Health Nutr 2002;5:245251.

33 Puska PVE, Laatikainen T, Jousilahti P, Paavola M (eds): The North Karelia Project: From North Karelia to National Action. Helsinki, Helsinki University Printing House, 2009.

34 EPODE: The EPODE Programme. www.epode-european-network.com (last accessed January 15, 2015).

-35 Wills J, Crichton N, Lorenc A, Kelly M: Using population segmentation to inform local obesity strategy in England. Health Promot Int 2014; doi: 10.1093/heapro/dau004

-36 Kumanyika SK, Obarzanek E, Stevens VJ, Hebert PR, Whelton PK: Weight-loss experience of black and white participants in NHLBI-sponsored clinical trials. Am J Clin Nutr 1991;53(6 suppl):1631S-1638S.

-37 West DS, Elaine Prewitt T, Bursac Z, Felix HC: Weight loss of black, white, and Hispanic men and women in the Diabetes Prevention Program. Obesity (Silver Spring) 2008;16:1413-1420.

-38 Lim SS, Vos T, Flaxman AD, Danaei G, Shibuya K, et al: A comparative risk assessment of burden of disease and injury attributable to 67 risk factors and risk factor clusters in 21 regions, 1990-2010: a systematic analysis for the Global Burden of Disease Study 2010. Lancet 2012;380:2224-2260.

39 World Health Organization (WHO/Europe): European Charter on Counteracting Obesity. Geneva, World Health Organization, 2006. www.euro.who.int/en/health-topics/disease-prevention/physical-activity/publications/2006/european-charter-on-counteracting-obesity-2006 (last accessed January 15, 2015).

-40 Jakicic JM, Jaramillo SA, Balasubramanyam A, Bancroft B, Curtis JM, Mathews A, Pereira M, Regensteiner JG, Ribisl PM: Effect of a lifestyle intervention on change in cardiorespiratory fitness in adults with type 2 diabetes: results from the Look AHEAD Study. Int J Obes (Lond) 2009;33:305-316.

-41 Wing RR, Bolin P, Brancati FL, Bray GA, Clark JM, Coday M, Crow RS, Curtis JM, Egan CM, Espeland MA, Evans M, Foreyt JP, Ghazarian S, Gregg EW, Harrison B, Hazuda HP, Hill JO, Horton ES, Hubbard VS, Jakicic JM, Jeffery RW, Johnson KC, Kahn SE, Kitabchi AE, Knowler WC, Lewis CE, Maschak-Carey BJ, Montez MG, Murillo A, Nathan DM, Patricio J, Peters A, Pi-Sunyer X, Pownall H, Reboussin D, Regensteiner JG, Rickman AD, Ryan DH, Safford M, Wadden TA, Wagenknecht LE, West DS, Williamson DF, Yanovski SZ: Cardiovascular effects of intensive lifestyle intervention in type 2 diabetes. N Engl J Med 2013;369:145-154.

-42 Look AHEAD Research Group: Eight-year weight losses with an intensive lifestyle intervention: the look AHEAD study. Obesity (Silver Spring) 2014;22:5-13.

-43 Yumuk V, Fruhbeck G, Oppert JM, Woodward E, Toplak H: An EASO position statement on multidisciplinary obesity management in adults. Obes Facts 2014;7:96-101.

44 Galbraith-Emami S, Lobstein T: The impact of initiatives to limit the advertising of food and beverage products to children: a systematic review. Obes Rev 2013;14:960-974.

45 Moodie R, Stuckler D, Monteiro C, Sheron N, Neal B, Thamarangsi T, Lincoln P, Casswell S: Profits and pandemics: prevention of harmful effects of tobacco, alcohol, and ultra-processed food and drink industries. Lancet 2013;381:670-679.

$\checkmark 46$ Jou J, Techakehakij W: International application of sugar-sweetened beverage (SSB) taxation in obesity reduction: factors that may influence policy effectiveness in country-specific contexts. Health Policy 2012; 107:83-90.

47 Fletcher JM, Frisvold D, Tefft N: Can soft drink taxes reduce population weight? Contemp Econ Policy 2010; 28:23-35.

48 Block JP, Willett WC: Taxing sugar-sweetened beverages: not a 'holy grail' but a cup at least half comment on 'food taxes: a new holy grail?'. Int J Health Policy Manag 2013;1:183-185.

-49 Wang YC, Bleich SN, Gortmaker SL: Increasing caloric contribution from sugar-sweetened beverages and 100\% fruit juices among US children and adolescents, 1988-2004. Pediatrics 2008;121:e1604-1614.

50 Basu S, Vellakkal S, Agrawal S, Stuckler D, Popkin B, Ebrahim S: Averting obesity and type 2 diabetes in India through sugar-sweetened beverage taxation: an economic-epidemiologic modeling study. PLoS Med 2014; 11:e1001582.

51 Briggs AD, Mytton OT, Kehlbacher A, Tiffin R, Rayner M, Scarborough P: Overall and income specific effect on prevalence of overweight and obesity of $20 \%$ sugar sweetened drink tax in UK: econometric and comparative risk assessment modelling study. BMJ 2013;347:f6189.

52 Hu FB, Malik VS: Sugar-sweetened beverages and risk of obesity and type 2 diabetes: epidemiologic evidence. Physiol Behav 2010;100:47-54.

53 Popkin BM: Sugary beverages represent a threat to global health. Trends Endocrinol Metab 2012;23:591-593.

54 Te Morenga L, Mallard S, Mann J: Dietary sugars and body weight: systematic review and meta-analyses of randomised controlled trials and cohort studies. BMJ 2013;346:e7492.

55 Rippe JM: The metabolic and endocrine response and health implications of consuming sugar-sweetened beverages: findings from recent randomized controlled trials. Adv Nutr 2013;4:677-686.

56 Kaiser KA, Shikany JM, Keating KD, Allison DB: Will reducing sugar-sweetened beverage consumption reduce obesity? Evidence supporting conjecture is strong, but evidence when testing effect is weak. Obes Rev 2013; 14:620-633.

57 Vartanian LR, Schwartz MB, Brownell KD: Effects of soft drink consumption on nutrition and health: a systematic review and meta-analysis. Am J Public Health 2007;97 667-675.

-58 Lesser LI, Ebbeling CB, Goozner M, Wypij D, Ludwig DS: Relationship between funding source and conclusion among nutrition-related scientific articles. PLoS Med 2007;4:e5. 
Lafontan et al.: Opportunities for Intervention Strategies for Weight Management: Global Actions on Fluid Intake Patterns

59 Bes-Rastrollo M, Schulze MB, Ruiz-Canela M, Martinez-Gonzalez MA: Financial conflicts of interest and reporting bias regarding the association between sugar-sweetened beverages and weight gain: a systematic review of systematic reviews. PLoS Med 2013;10:e1001578.

60 Bray GA, Popkin BM: Calorie-sweetened beverages and fructose: what have we learned 10 years later. Pediatr Obes 2013;8:242-248.

61 Green AK, Jacques PF, Rogers G, Fox CS, Meigs JB, McKeown NM: Sugar-sweetened beverages and prevalence of the metabolically abnormal phenotype in the Framingham Heart Study. Obesity (Silver Spring) 2014; doi: 10.1002/oby.20724.

-62 Barrio-Lopez MT, Martinez-Gonzalez MA, Fernandez-Montero A, Beunza JJ, Zazpe I, Bes-Rastrollo M: Prospective study of changes in sugar-sweetened beverage consumption and the incidence of the metabolic syndrome and its components: the SUN cohort. Br J Nutr 2013;110:1722-1731.

63 Olsen NJ, Heitmann BL: Intake of calorically sweetened beverages and obesity. Obes Rev. 2009;10:68-75.

-64 Malik VS, Pan A, Willett WC, Hu FB: Sugar-sweetened beverages and weight gain in children and adults: a systematic review and meta-analysis. Am J Clin Nutr 2013;98:1084-1102.

-65 Qi Q, Chu AY, Kang JH, Jensen MK, Curhan GC, Pasquale LR, Ridker PM, Hunter DJ, Willett WC, Rimm EB, Chasman DI, Hu FB, Qi L: Sugar-sweetened beverages and genetic risk of obesity. N Engl J Med 2012;367: 1387-1396.

66 Zheng M, Rangan A, Olsen NJ, Bo Andersen L, Wedderkopp N, Kristensen P, Grontved A, Ried-Larsen M, Lempert SM, Allman-Farinelli M, Heitmann BL: Sugar-sweetened beverages consumption in relation to changes in body fatness over 6 and 12 years among 9-year-old children: the European Youth Heart Study. Eur J Clin Nutr 2014;68:77-83.

-67 Richelsen B: Sugar-sweetened beverages and cardio-metabolic disease risks. Curr Opin Clin Nutr Metab Care 2013;16:478-484.

68 Goran MI, Dumke K, Bouret SG, Kayser B, Walker RW, Blumberg B: The obesogenic effect of high fructose exposure during early development. Nat Rev Endocrinol 2013;9:494-500.

69 de Ruyter JC, Olthof MR, Seidell JC, Katan MB: A trial of sugar-free or sugar-sweetened beverages and body weight in children. N Engl J Med 2012;367:1397-1406.

70 Nooyens AC, Visscher TL, Schuit AJ, van Rossum CT, Verschuren WM, van Mechelen W, Seidell JC: Effects of retirement on lifestyle in relation to changes in weight and waist circumference in Dutch men: a prospective study. Public Health Nutr 2005;8:1266-1274.

71 Viner RM, Cole TJ: Who changes body mass between adolescence and adulthood? Factors predicting change in BMI between 16 year and 30 years in the 1970 British Birth Cohort. Int J Obes (Lond) 2006;30:1368-1374.

-72 Bes-Rastrollo M, Sanchez-Villegas A, Gomez-Gracia E, Martinez JA, Pajares RM, Martinez-Gonzalez MA: Predictors of weight gain in a Mediterranean cohort: the Seguimiento Universidad de Navarra Study 1. Am J Clin Nutr 2006;83:362-370.

-73 Reid M, Hammersley R, Hill AJ, Skidmore P: Long-term dietary compensation for added sugar: effects of supplementary sucrose drinks over a 4-week period. Br J Nutr 2007;97:193-203.

74 Romaguera D, Angquist L, Du H, Jakobsen MU, Forouhi NG, Halkjaer J, Feskens EJ, van der AD, Masala G, Steffen A, Palli D, Wareham NJ, Overvad K, Tjonneland A, Boeing H, Riboli E, Sorensen TI: Food composition of the diet in relation to changes in waist circumference adjusted for body mass index. PLoS One. 2011;6:e23384.

75 Yang Q, Zhang Z, Gregg EW, Flanders WD, Merritt R, Hu FB: Added sugar intake and cardiovascular diseases mortality among US adults. JAMA Intern Med 2014;174:516-524.

76 Park S, Onufrak S, Sherry B, Blanck HM: The relationship between health-related knowledge and sugarsweetened beverage intake among US adults. J Acad Nutr Diet 2013;114:1059-1066.

77 Gardner C: Non-nutritive sweeteners: evidence for benefit vs. risk. Curr Opin Lipidol 2014;25:80-84.

78 Gardner C, Wylie-Rosett J, Gidding SS, Steffen LM, Johnson RK, Reader D, Lichtenstein AH: Nonnutritive sweeteners: current use and health perspectives: a scientific statement from the American Heart Association and the American Diabetes Association. Diabetes Care 2012;35:1798-1808.

79 Mozaffarian D, Hao T, Rimm EB, Willett WC, Hu FB: Changes in diet and lifestyle and long-term weight gain in women and men. N Engl J Med 2011;364:2392-2404.

-80 Raben A, Vasilaras TH, Moller AC, Astrup A: Sucrose compared with artificial sweeteners: different effects on ad libitum food intake and body weight after $10 \mathrm{wk}$ of supplementation in overweight subjects. Am J Clin Nutr 2002;76:721-729.

-81 Fowler SP, Williams K, Resendez RG, Hunt KJ, Hazuda HP, Stern MP: Fueling the obesity epidemic? Artificially sweetened beverage use and long-term weight gain. Obesity (Silver Spring) 2008;16:1894-1900.

82 Foreyt J, Kleinman R, Brown RJ, Lindstrom R: The use of low-calorie sweeteners by children: implications for weight management. J Nutr 2012;142:1155S-1162S.

-83 Anderson GH, Foreyt J, Sigman-Grant M, Allison DB: The use of low-calorie sweeteners by adults: impact on weight management. J Nutr 2012;142:1163S-1169S.

84 Renwick AG, Molinary SV: Sweet-taste receptors, low-energy sweeteners, glucose absorption and insulin release. Br J Nutr 2010;104:1415-1420.

85 European Food Safety Authority: Scientific opinion on the re-evaluation of aspartame (E951) as a food additive. EFSA J 2013;11:3496.www.efsa.europa.eu/fr/efsajournal/doc/3496.pdf (last accessed January 15, 2015). 
Lafontan et al:: Opportunities for Intervention Strategies for Weight Management:

Global Actions on Fluid Intake Patterns

86 Acharya AB, Satyanarayan A, Thakur SL: Status of association studies linking diabetes mellitus and periodontal disease in India. Int J Diabetes Dev Ctries 2010;30:69-74.

87 Pepino MY, Bourne C: Non-nutritive sweeteners, energy balance, and glucose homeostasis. Curr Opin Clin Nutr Metab Care 2011;14:391-395.

-88 Muegge BD, Kuczynski J, Knights D, Clemente JC, Gonzalez A, Fontana L, Henrissat B, Knight R, Gordon JI: Diet drives convergence in gut microbiome functions across mammalian phylogeny and within humans. Science 2011;332:970-974.

89 Faith JJ, McNulty NP, Rey FE, Gordon JI: Predicting a human gut microbiota's response to diet in gnotobiotic mice. Science 2011;333:101-104.

90 Brown K, DeCoffe D, Molcan E, Gibson DL: Diet-induced dysbiosis of the intestinal microbiota and the effects on immunity and disease. Nutrients 2012;4:1095-1119.

91 Payne AN, Chassard C, Lacroix C: Gut microbial adaptation to dietary consumption of fructose, artificial sweeteners and sugar alcohols: implications for host-microbe interactions contributing to obesity. Obes Rev 2012; 13:799-809.

92 Kant AK, Graubard BI, Atchison EA: Intakes of plain water, moisture in foods and beverages, and total water in the adult US population - nutritional, meal pattern, and body weight correlates: National Health and Nutrition Examination Surveys 1999-2006. Am J Clin Nutr 2009;90:655-663.

-93 Dennis EA, Dengo AL, Comber DL, Flack KD, Savla J, Davy KP, Davy BM: Water consumption increases weight loss during a hypocaloric diet intervention in middle-aged and older adults. Obesity (Silver Spring) 2010;18: 300-307.

$\$ 94$ Dennis EA, Flack KD, Davy BM: Beverage consumption and adult weight management: a review. Eat Behav 2009;10:237-246.

95 Daniels MC, Popkin BM: Impact of water intake on energy intake and weight status: a systematic review. Nutr Rev 2010;68:505-521.

96 Muckelbauer R, Sarganas G, Gruneis A, Muller-Nordhorn J: Association between water consumption and body weight outcomes: a systematic review. Am J Clin Nutr 2013;98:282-299.

-97 Onufrak SJ, Park S, Sharkey JR, Sherry B: The relationship of perceptions of tap water safety with intake of sugar-sweetened beverages and plain water among US adults. Public Health Nutr 2012:17:179-185.

-98 Pan A, Malik VS, Hao T, Willett WC, Mozaffarian D, Hu FB: Changes in water and beverage intake and long-term weight changes: results from three prospective cohort studies. Int J Obes (Lond) 2013;37:1378-1385.

-99 Visscher TL, van Hal WC, Blokdijk L, Seidell JC, Renders CM, Bemelmans WJ: Feasibility and impact of placing water coolers on sales of sugar-sweetened beverages in Dutch secondary school canteens. Obes Facts 2010; 3:109-115.

100 Akers JD, Cornett RA, Savla JS, Davy KP, Davy BM: Daily self-monitoring of body weight, step count, fruit/ vegetable intake, and water consumption: a feasible and effective long-term weight loss maintenance approach. J Acad Nutr Diet 2012;112:685-692. e2.

101 Sofi MH, Gudi R, Karumuthil-Melethil S, Perez N, Johnson BM, Vasu C: pH of drinking water influences the composition of gut microbiome and type 1 diabetes incidence. Diabetes 2014;63:632-644.

102 Boschmann M, Steiniger J, Hille U, Tank J, Adams F, Sharma AM, Klaus S, Luft FC, Jordan J: Water-induced thermogenesis. J Clin Endocrinol Metab 2003;88:6015-6019.

103 Boschmann M, Steiniger J, Franke G, Birkenfeld AL, Luft FC, Jordan J: Water drinking induces thermogenesis through osmosensitive mechanisms. J Clin Endocrinol Metab 2007;92:3334-3337.

104 Lipp A, Tank J, Franke G, Arnold G, Luft FC, Jordan J: Osmosensitive mechanisms contribute to the water drinking-induced pressor response in humans. Neurology 2005;65:905-907.

105 McHugh J, Keller NR, Appalsamy M, Thomas SA, Raj SR, Diedrich A, Biaggioni I, Jordan J, Robertson D: Portal osmopressor mechanism linked to transient receptor potential vanilloid 4 and blood pressure control. Hypertension 2010;55:1438-1443.

106 May M, Jordan J: The osmopressor response to water drinking. Am J Physiol Regul Integr Comp Physiol 2011; 300:R40-46.

107 Vij VA, Joshi AS: Effect of 'water induced thermogenesis' on body weight, body mass index and body composition of overweight subjects. J Clin Diagn Res 2013;7:1894-1896.

108 Brown CM, Dulloo AG, Montani JP: Water-induced thermogenesis reconsidered: the effects of osmolality and water temperature on energy expenditure after drinking. J Clin Endocrinol Metab 2006;91:3598-3602.

109 Kocelak P, Zak-Golab A, Rzemieniuk A, Smetek J, Sordyl R, Tyrka A, Sosnowski M, Zahorska-Markiewicz B, Chudek J, Olszanecka-Glinianowicz M: The influence of oral water load on energy expenditure and sympathovagal balance in obese and normal weight women. Arch Med Sci 2012;8:1003-1008.

110 Maughan RJ, Griffin J: Caffeine ingestion and fluid balance: a review. J Hum Nutr Diet 2003;16:411-420.

111 Vernarelli JA, Lambert JD: Tea consumption is inversely associated with weight status and other markers for metabolic syndrome in US adults. Eur J Nutr 2013;52:1039-1048.

112 Cardoso GA, Salgado JM, Cesar Mde C, Donado-Pestana CM: The effects of green tea consumption and resistance training on body composition and resting metabolic rate in overweight or obese women. J Med Food 2013;16:120-127.

113 Thornton SN: Thirst and hydration: physiology and consequences of dysfunction. Physiol Behav 2010;100: 15-21.

114 Noakes TD: Is drinking to thirst optimum? Ann Nutr Metab 2010;57(suppl 2):9-17. 
Lafontan et al.: Opportunities for Intervention Strategies for Weight Management: Global Actions on Fluid Intake Patterns

115 Millard-Stafford M, Wendland DM, O’Dea NK, Norman TL: Thirst and hydration status in everyday life. Nutr Rev 2012;70(suppl 2):S147-151.

116 Baker LB, Jeukendrup AE: Optimal composition of fluid-replacement beverages. Compr Physiol 2014;4:575620.

117 McCauley LR, Dyer AJ, Stern K, Hicks T, Nguyen MM: Factors influencing fluid intake behavior among kidney stone formers. J Urol 2012;187:1282-1286.

118 Valtin H: 'Drink at least eight glasses of water a day.' Really? Is there scientific evidence for '8 × 8'? Am J Physiol Regul Integr Comp Physiol 2002;283:R993-1004.

119 Sawka MN, Cheuvront SN, Carter R 3rd: Human water needs. Nutr Rev 2005;63:S30-39.

120 Kenefick RW, Sawka MN: Hydration at the work site. J Am Coll Nutr 2007;26(5 suppl):597S-603S.

-121 Armstrong LE, Barquera S, Duhamel J-F, Hardinsyah R, Haslam S, Lafontan M: Recommendations for healthier hydration: addressing the public health issues of obesity and type 2 diabetes. Clin Obes 2013;2:115-124.

122 European Food Safety Authority: Scientific opinion on dietary reference values for water. EFSA J 2010;8:1459 www.efsa.europa.eu/en/scdocs/scdoc/1459.htm (last accessed January 15, 2015).:

123 Manz F, Johner SA, Wentz A, Boeing H, Remer T: Water balance throughout the adult life span in a German population. Br J Nutr 2012;107:1673-1681.

124 Zizza CA, Ellison KJ, Wernette CM: Total water intakes of community-living middle-old and oldest-old adults. J Gerontol A Biol Sci Med Sci 2009;64:481-486.

125 Ferry M: Strategies for ensuring good hydration in the elderly. Nutr Rev 2005;63:S22-29.

126 Godfrey H, Cloete J, Dymond E, Long A: An exploration of the hydration care of older people: a qualitative study. Int J Nurs Stud 2012;49:1200-1211.

127 Peters EM: Nutritional aspects in ultra-endurance exercise. Curr Opin Clin Nutr Metab Care 2003;6:427-434.

128 Hill JO, Melanson EL: Overview of the determinants of overweight and obesity: current evidence and research issues. Med Sci Sports Exerc 1999;31(11 suppl):S515-521.

129 Brownson RC, Boehmer TK, Luke DA: Declining rates of physical activity in the United States: what are the contributors? Annu Rev Public Health 2005;26:421-443.

130 Swinburn B, Sacks G, Ravussin E: Increased food energy supply is more than sufficient to explain the US epidemic of obesity. Am J Clin Nutr 2009;90:1453-1456.

131 Owen N, Healy GN, Matthews CE, Dunstan DW: Too much sitting: the population health science of sedentary behavior. Exerc Sport Sci Rev 2010;38:105-113.

132 Matthews CE, George SM, Moore SC, Bowles HR, Blair A, Park Y, Troiano RP, Hollenbeck A, Schatzkin A: Amount of time spent in sedentary behaviors and cause-specific mortality in US adults. Am J Clin Nutr 2012;95:437-445.

133 Luke A, Cooper RS: Physical activity does not influence obesity risk: time to clarify the public health message. Int J Epidemiol 2013;42:1831-1836.

134 Blair SN, Archer E, Hand GA: Commentary: Luke and Cooper are wrong: physical activity has a crucial role in weight management and determinants of obesity. Int J Epidemiol 2013;42:1836-1838.

135 Delany JP, Kelley DE, Hames KC, Jakicic JM, Goodpaster BH: Effect of physical activity on weight loss, energy expenditure, and energy intake during diet induced weight loss. Obesity (Silver Spring) 2014;22:363-370.

136 Hankinson AL, Daviglus ML, Bouchard C, Carnethon M, Lewis CE, Schreiner PJ, Liu K, Sidney S: Maintaining a high physical activity level over 20 years and weight gain. JAMA 2010;304:2603-2610.

137 Donnelly JE, Blair SN, Jakicic JM, Manore MM, Rankin JW, Smith BK: American College of Sports Medicine Position Stand. Appropriate physical activity intervention strategies for weight loss and prevention of weight regain for adults. Med Sci Sports Exerc 2009;41:459-471.

138 Walhin JP, Richardson JD, Betts JA, Thompson D: Exercise counteracts the effects of short-term overfeeding and reduced physical activity independent of energy imbalance in healthy young men. J Physiol 2013;591: 6231-6243.

139 Church TS, Thomas DM, Tudor-Locke C, Katzmarzyk PT, Earnest CP, Rodarte RQ, Martin CK, Blair SN, Bouchard C: Trends over 5 decades in U.S. occupation-related physical activity and their associations with obesity. PLoS One 2011;6:e19657.

140 Archer E, Shook RP, Thomas DM, Church TS, Katzmarzyk PT, Hebert JR, McIver KL, Hand GA, Lavie CJ, Blair SN: 45-Year trends in women's use of time and household management energy expenditure. PLoS One 2013; 8:e56620.

141 Archer E, Hand GA, Hebert JR, Lau EY, Wang X, Shook RP, Fayad R, Lavie CJ, Blair SN: Validation of a novel protocol for calculating estimated energy requirements and average daily physical activity ratio for the US population: 2005-2006. Mayo Clin Proc 2013;88:1398-1407.

142 Archer E, Lavie CJ, McDonald SM, Thomas DM, Hebert JR, Taverno Ross SE, McIver KL, Malina RM, Blair SN: Maternal inactivity: 45-year trends in mothers' use of time. Mayo Clin Proc 2013;88:1368-1377.

143 Laskowski ER: The role of exercise in the treatment of obesity. PM R 2012;4:840-844.

144 Weinsier RL, Hunter GR, Zuckerman PA, Redden DT, Darnell BE, Larson DE, Newcomer BR, Goran MI: Energy expenditure and free-living physical activity in black and white women: comparison before and after weight loss. Am J Clin Nutr 2000;71:1138-1146.

145 Gill JM, Celis-Morales CA, Ghouri N: Physical activity, ethnicity and cardio-metabolic health: does one size fit all? Atherosclerosis 2014;232:319-333.

146 Swift DL, Johannsen NM, Lavie CJ, Earnest CP, Church TS: The role of exercise and physical activity in weight loss and maintenance. Prog Cardiovasc Dis 2014;56:441-447. 
Lafontan et al.: Opportunities for Intervention Strategies for Weight Management:

Global Actions on Fluid Intake Patterns

147 Ross R, Bradshaw AJ: The future of obesity reduction: beyond weight loss. Nat Rev Endocrinol 2009;5:319325.

148 Thompson D, Karpe F, Lafontan M, Frayn K: Physical activity and exercise in the regulation of human adipose tissue physiology. Physiol Rev 2012;92:157-191.

149 Herzig KH, Ahola R, Leppaluoto J, Jokelainen J, Jamsa T, Keinanen-Kiukaanniemi S: Light physical activity determined by a motion sensor decreases insulin resistance, improves lipid homeostasis and reduces visceral fat in high-risk subjects: PreDiabEx study RCT. Int J Obes (Lond) 2014;38:1089-1096.

150 Lee S, Deldin AR, White D, Kim Y, Libman I, Rivera-Vega M, Kuk JL, Sandoval S, Boesch C, Arslanian S: Aerobic exercise but not resistance exercise reduces intrahepatic lipid content and visceral fat and improves insulin sensitivity in obese adolescent girls: a randomized controlled trial. Am J Physiol Endocrinol Metab 2013; 305:E1222-1229.

151 Dutheil F, Lac G, Lesourd B, Chapier R, Walther G, Vinet A, Sapin V, Verney J, Ouchchane L, Duclos M, Obert P, Courteix D: Different modalities of exercise to reduce visceral fat mass and cardiovascular risk in metabolic syndrome: the RESOLVE randomized trial. Int J Cardiol 2013;168:3634-3642.

152 Stubbs RJ, Sepp A, Hughes DA, Johnstone AM, King N, Horgan G, Blundell JE: The effect of graded levels of exercise on energy intake and balance in free-living women. Int J Obes Relat Metab Disord 2002;26:866-869.

153 Earnest CP, Johannsen NM, Swift DL, Gillison FB, Mikus CR, Lucia A, Kramer K, Lavie CJ, Church TS: Aerobic and strength training in concomitant metabolic syndrome and type 2 diabetes. Med Sci Sports Exerc 2014;46: 1293-1301.

154 Centers for Disease Control and Prevention: Physical Activity and Health. www.cdc.gov/physicalactivity/ everyone/health/index.html (last accessed January 15, 2015).

155 World Health Organization Europe: Physical Activity and Health in Europe: www.euro.who.int/_data/assets/ pdf_file/0011/87545/E89490.pdf (last accessed January 15, 2015).

156 Deaprtment of Health: UK physical activity guidelines. www.gov.uk/government/publications/uk-physicalactivity-guidelines (last accessed January 15, 2015).

157 Farpour-Lambert NJ, Aggoun Y, Marchand LM, Martin XE, Herrmann FR, Beghetti M: Physical activity reduces systemic blood pressure and improves early markers of atherosclerosis in pre-pubertal obese children. J Am Coll Cardiol 2009;54:2396-2406.

158 Manolopoulos KN, Karpe F, Frayn KN: Gluteofemoral body fat as a determinant of metabolic health. Int J Obes (Lond) 2010;34:949-959.

159 Manolopoulos KN, Karpe F, Frayn KN: Marked resistance of femoral adipose tissue blood flow and lipolysis to adrenaline in vivo. Diabetologia 2012;55:3029-3037.

160 Sawka MN, Burke LM, Eichner ER, Maughan RJ, Montain SJ, Stachenfeld NS: American College of Sports Medicine position stand. Exercise and fluid replacement. Med Sci Sports Exerc 2007;39:377-390.

161 Walsh RM, Noakes TD, Hawley JA, Dennis SC: Impaired high-intensity cycling performance time at low levels of dehydration. Int J Sports Med 1994;15:392-398.

162 Cheuvront SN, Kenefick RW, Montain SJ, Sawka MN: Mechanisms of aerobic performance impairment with heat stress and dehydration. J Appl Physiol 2010;109:1989-1995.

163 Coyle EF: Fluid and fuel intake during exercise. J Sports Sci 2004;22:39-55.

164 Achten J, Jeukendrup AE: Optimizing fat oxidation through exercise and diet. Nutrition 2004;20:716-727.

165 Goldstein ER, Ziegenfuss T, Kalman D, Kreider R, Campbell B, Wilborn C, Taylor L, Willoughby D, Stout J, Graves BS, Wildman R, Ivy JL, Spano M, Smith AE, Antonio J: International Society of Sports Nutrition position stand: caffeine and performance. J Int Soc Sports Nutr 2010;7:5.

166 Park S, Onufrak S, Blanck HM, Sherry B: Characteristics associated with consumption of sports and energy drinks among US adults: National Health Interview Survey, 2010. J Acad Nutr Diet 2013;113:112-119.

167 Campbell B, Wilborn C, La Bounty P, Taylor L, Nelson MT, Greenwood M, Ziegenfuss TN, Lopez HL, Hoffman JR, Stout JR, Schmitz S, Collins R, Kalman DS, Antonio J, Kreider RB: International Society of Sports Nutrition position stand: energy drinks. J Int Soc Sports Nutr 2013;10:1.

168 Huy C, Becker S, Gomolinsky U, Klein T, Thiel A: Health, medical risk factors, and bicycle use in everyday life in the over-50 population. J Aging Phys Act 2008;16:454-464.

169 Saelens BE, Sallis JF, Frank LD: Environmental correlates of walking and cycling: findings from the transportation, urban design, and planning literatures. Ann Behav Med 2003;25:80-91.

170 Cho G, Rodriguez DA, Khattak AJ: The role of the built environment in explaining relationships between perceived and actual pedestrian and bicyclist safety. Accid Anal Prev 2009;41:692-702.

171 McGinn AP, Evenson KR, Herring AH, Huston SL, Rodriguez DA: Exploring associations between physical activity and perceived and objective measures of the built environment. J Urban Health 2007;84:162-184.

172 Pucher J, Buehler R, Merom D, Bauman A: Walking and cycling in the United States, 2001-2009: evidence from the National Household Travel Surveys. Am J Public Health 2011;101(suppl 1):S310-317.

173 Stuckler D, Nestle M: Big food, food systems, and global health. PLoS Med 2012; 9:e1001242.

174 Kleiman S, Ng SW, Popkin B: Drinking to our health: can beverage companies cut calories while maintaining profits? Obes Rev 2012;13:258-274.

175 Dorfman L, Cheyne A, Friedman LC, Wadud A, Gottlieb M: Soda and tobacco industry corporate social responsibility campaigns: how do they compare? PLoS Med 2012;9:e1001241. 